\title{
Sending the herd off the cliff edge: the disturbing interaction between herding and market-sensitive risk management practices ${ }^{1}$ \\ Avinash Persaud, State Street
}

\begin{abstract}
Summary
In the international financial arena, G7 policymakers chant three things: more market-sensitive risk management, stronger prudential standards and improved transparency. The message is that we do not need a new world order, but we can improve the workings of the existing one. While many believe this is an inadequate response to the financial crises of the last two decades, few argue against risk management, prudence and transparency. Perhaps we should, especially with regards to marketsensitive risk management and transparency. The underlying idea behind this holy trinity is that it better equips markets to reward good behaviour and penalise the bad, across governments and market players. However, while the market is discerning in the long-run, there is now compelling evidence that in the short run, market participants find it hard to distinguish between the good and the unsustainable; they herd; and contagion is common.

Critically, in a herding environment, tighter market-sensitive risk management systems and more transparency actually makes markets less stable and more prone to crisis. This perverse response may help to explain the growing instability of the financial system. Over the past ten years the system has been in crisis in almost four. In response, the emphasis on market sensitive risk management practices and transparency must be tempered rather than extended vis-a-vis credit ratings agencies and the risk management of investors. The incentives of regulators should be realigned to include the impact of herding behaviour on foreign markets as well as local institutions. Financial market institutions should be encouraged to set aside collateral for systemic risk or to buy liquidity options from central banks during good times. Countries should facilitate the inflow of capital from investors who herd least or leave slowly: foreign direct investors, equity portfolio investors and, surprisingly, hedge funds.
\end{abstract}

\section{A cyclical debate}

The debate on reform of the international financial system follows a cycle. In the middle of each crisis - and there have been at least six since the Debt Crisis which started in Mexico in 1982 - there are deafening demands for the whole-scale reform of the entire international financial system. A few months on from the end of each crisis and those demands fade. There were clear and present parallels between calls made in previous crises and those made in the thick of the last crisis, for the IMF to become a lender of last resort, injecting substantial liquidity in times of crisis, and for hedge funds to be regulated. Every crisis inspires plans for a new financial architecture and as the crisis ends, most of these plans are tidied away.

1 This essay won first prize in the Institute of International Finance's Jacques de Larosiere Awards in Global Finance 2000. 
Table 1

Global financial crises in the 1990s

\begin{tabular}{c|l|l}
\hline \multicolumn{1}{c|}{ Date } & \multicolumn{1}{|c}{ Crisis } & \multicolumn{1}{c}{$\begin{array}{c}\text { Countries where the real exchange rate fell by } \\
\text { more than 10\% over one month }\end{array}$} \\
\hline $1992-1993$ & "EMS" & $\begin{array}{l}\text { UK, Italy, Spain, Portugal, Sweden, Finland, Denmark, Norway, Belgium, France, } \\
\text { Ireland, India, Venezuela }\end{array}$ \\
\hline $1994-1995$ & "Tequila" & Columbia, Venezuela, Mexico, Turkey, Japan \\
\hline $1997-1999$ & "Asia" & $\begin{array}{l}\text { Thailand, Philippines, Indonesia, Malaysia, Taiwan, Korea, Brazil Columbia, Israel, } \\
\text { Peru, South Africa, Zimbabwe, Russia, Sweden, Switzerland, Spain }\end{array}$ \\
\hline
\end{tabular}

Source: State Street Bank.

Underlying this cycle of debate is that while the demand to make systemic changes is naturally strong in the middle of a crisis, the consensus on what is wrong and what to do is generally weak. Moreover, while recent crises have appeared sharper and more global than before, they have been shorter-lived. Before a consensus on what to do to avoid crises can grow, they are over, and countries previously in crisis begin to enjoy economic rebound and the return of international capital flows. This was not the case during the Latin-American Debt Crisis of the mid-1980s or after the EMS crisis in 1992-93 when economic recovery was held back by a cheap dollar and European governments exerting fiscal restraint. But it was the case in the last two crises in Mexico and Asia, see Chart 1. We also live in an age where ambitions are limited. We no longer walk on the moon. In this environment, the view that often gains ground a few months after the crisis is that there are risks to meddling with a financial system that works most of the time and there are things that can be safely done to improve the workings of the market the rest of the time.

Chart 1

The rapid rebound in Asian GDP

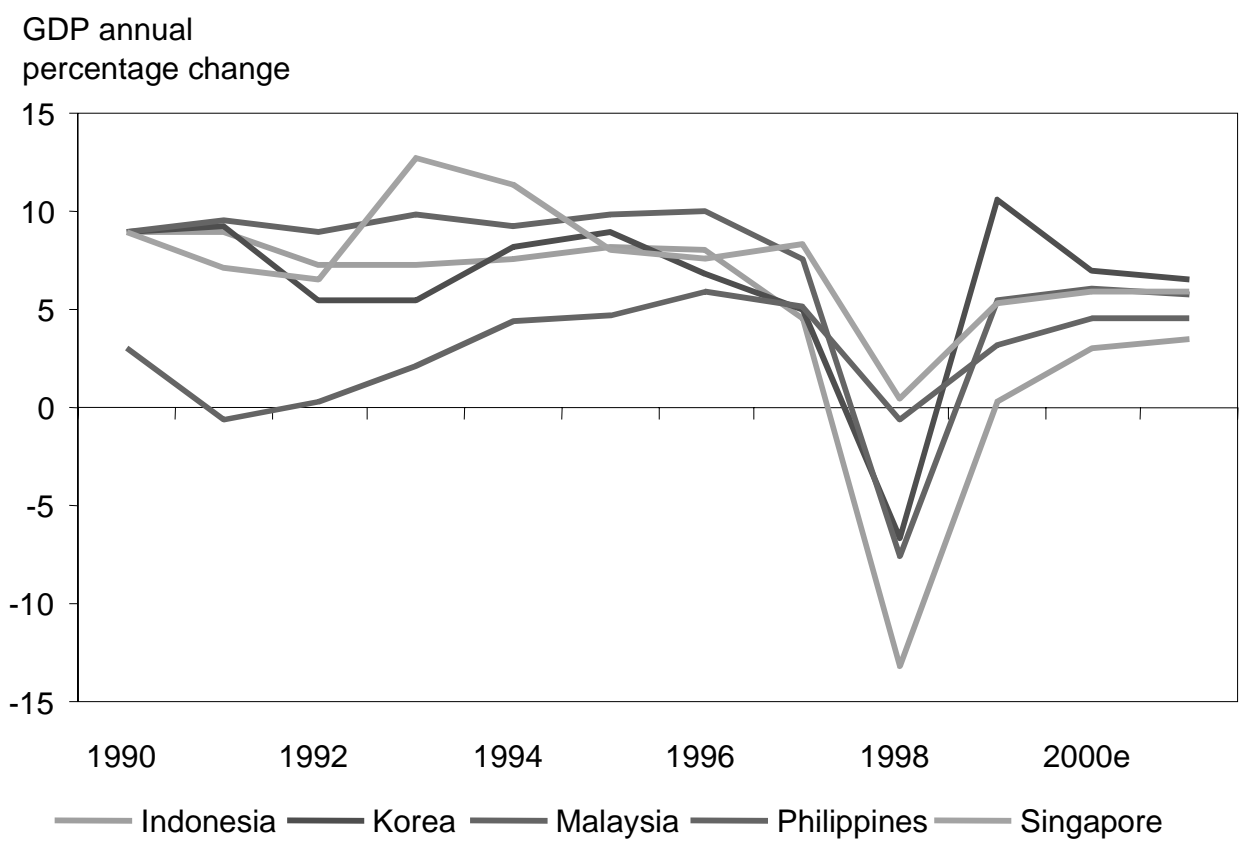

Source: State Street Bank. 
The proposals that emerge post-crisis, therefore, tend to focus on making it easier for the market to reward good behaviour and penalise the bad. The emphasis is not on changing the rules of the game, but on strengthening the players: stronger risk management, more prudential standards and improved transparency. One of the key responses of the Interim Committee of the IMF to the latest crisis and the desire to avoid a next one was the adoption on 26 September 1999 of a new Code of Good Practices on Transparency in Monetary and Financial Policies. Incidentally, these measures are all relatively inexpensive to implement. There is declining political support for large packages of tax-payers money to bail out foreign countries in trouble.

\section{How more market-sensitive risk management can create risk}

While many believe that market sensitive risk management, prudential standards and transparency are probably not enough to avoid future crises, they believe these measures will probably help to provide the right discipline for governments and can surely do no harm. These measures are likely to be a positive force in the long run when markets are better at discerning between the good and bad. But in the short-run, there is growing evidence that market participants find it hard to discern between the good and the unsustainable, they often herd and contagion from one crisis to another is common. The problem is that in a world of "herding", tighter market-sensitive risk management regulations and improved transparency can, perversely, turn events from bad to worse, creating volatility, reducing diversification and triggering contagion. How can this happen?

Let us explore the interaction between herding, market-sensitive risk management and transparency in bank lending. It is important to note that bank lending remains a powerful feature of modern-day crises. For example, the five Asian crisis countries - Thailand, Malaysia, South Korea, Indonesia and the Philippines - received USD 47.8 billion in foreign bank loans in 1996. In 1997, banks withdrew USD 29.9 billion, a net turnaround of almost USD 80 billion in one year. By contrast, equity portfolio flows remained positive throughout 1997, see "Portfolio Flow Indicator - Technical Document, State Street Bank and FDO Partners, 1999".

The growing fashion in risk management, supported by the Basel Committee on Banking Supervision, is a move away from discretionary judgements about risk and a move to more quantitative and marketsensitive approaches (for an early reference see, the Supervisory Treatment of Market Risks, Basel Committee on Banking Supervision, 1993). This is well illustrated by how banks now tend to manage market risks by setting a DEAR limit - daily earnings at risk. DEAR answers the question: how much can I lose with, say, a $1 \%$ probability over the next day. It is calculated by taking the bank's portfolio of positions and estimating the future distribution of daily returns based on past measures of market correlation and volatility. Both rising volatility and rising correlation will increase the potential loss of the portfolio, increasing DEAR. Falling volatility and correlation will do the opposite. Banks set a DEAR limit: the maximum dollar amount they are prepared to put at risk of losing with a $1 \%$ probability. When DEAR exceeds the limit, the bank reduces exposure, often by switching into less volatile and less correlated assets such as US dollar cash. (See RiskMetrics Technical Manual, RiskMetrics Group, London, 1999.)

By herding behaviour I mean that banks or investors like to buy what others are buying, sell what others are selling and own what others own. There are three main explanations for why bankers and investors herd. First, in a world of uncertainty, the best way of exploiting the information of others is by copying what they are doing. Second, bankers and investors are often measured and rewarded by relative performance so it literally does not pay a risk-averse player to stray too far from the pack. Third, investors and bankers are more likely to be sacked for being wrong and alone than being wrong and in company. (For further explanations of herding see Investor Behaviour in the October 1987 Stock Market Crash: Survey Evidence by R Shiller, NBER discussion paper 2446, 1990.) 


\section{Representation of VAR: histogram of portfolio values}

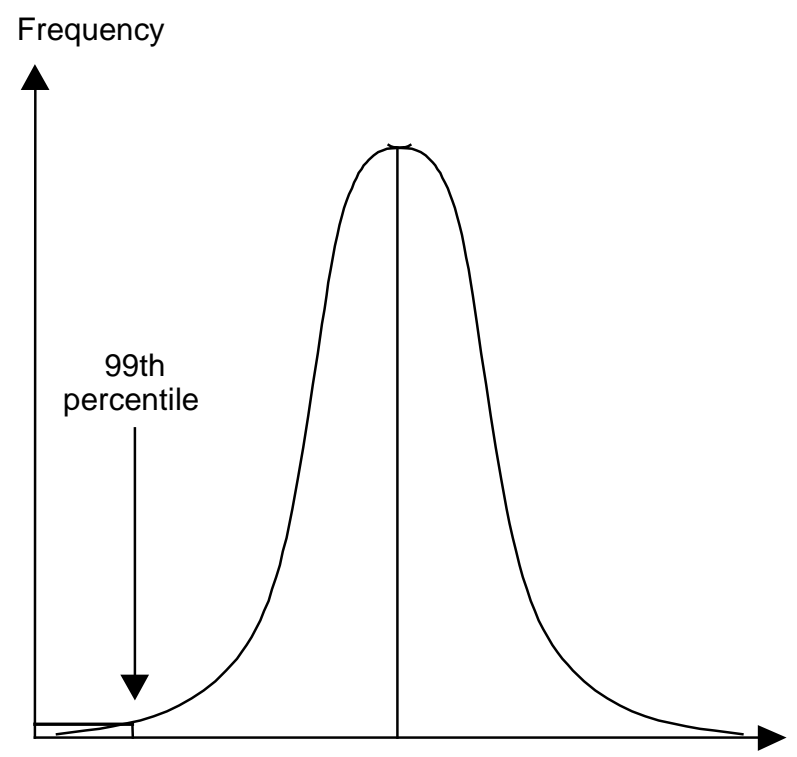

Current portfolio value

Imagine that over time a herd of banks have acquired stocks in two risky assets that have few fundamental connections, say, Korean property and UK technology stocks. Imagine too that some bad news causes volatility in UK technology stocks and the banks most heavily invested there find that their DEAR limits are hit. As these banks try and reduce their DEAR by selling the same stocks (Korean property and UK technology) at the very same time, there are dramatic declines in prices, rises in volatility in both markets and in the correlation between Korean and UK markets. Rising volatility and correlation triggers the DEAR limits of banks less heavily invested in these markets but invested in other markets. As they join the selling milieu, volatility, correlation and contagion rises.

The key to this environment is that market participants behave strategically in relation to one another, but DEAR measures risk "statically" - without strategic considerations. Previous volatility and correlations were measured over a period of time when the herd gradually built up and are therefore almost certain to underestimate the impact on prices, volatility and correlations when many investors sell the same asset at the same time. This strategic behaviour can be modeled more formally using game theory. (Some attempts to do so can be found in "Risk management with interdependent choice" by Stephen Morris and Hyun Song Shin, Oxford Review of Economic Policy, Autumn 1999.) 
Figure 2

A vicious cycle of herding and DEAR limits

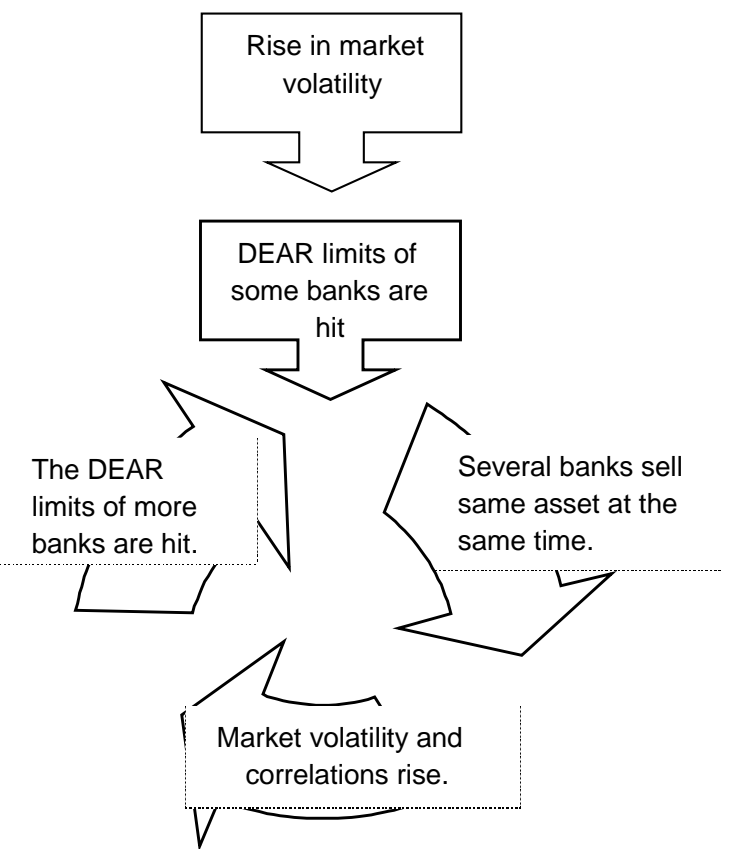

\section{Stress-testing}

It has been suggested that stress-testing could avoid this contagion - testing how a portfolio of positions perform under made-up scenarios. In practice it does not do so for two reasons. First, the most popular stress test is to see what would happen to a portfolio of positions if a past crisis was repeated. But this is not very meaningful. As we have observed above the spread and focus of crises relate to where positions are and unless positions are identical - which is unlikely given the memory of the past crisis - the next crisis will be different from the past. The best stress test is to assume that everybody has the same positions as you do and you cannot get out of any or them without large losses. This test is seldom attempted. It is hard to estimate the spread and depth of positions or the impact on liquidity and hence potential losses. In this age of quant, risk managers mistakenly prefer to worry about quantifiable risks than unquantifiable ones. Even if the risks could be estimated, banks would treat the result with suspicion. It would be like telling a lending institution that when assessing risk, assume none of the loans are repaid and the historical volatilities and correlation suggest it is a far-fetched scenario, though it is exactly the scenario that Long-Term Capital, the failed hedge fund, and others found themselves in during September and October of 1998.

Several financial institutions suffered serious losses in 1998, but few of these were life threatening. An additional critical point is that even if stress testing worked to save banks from trouble, it may not save a country. One of the interesting aspects of the Asian crisis was that while short-term external debt exposures for Asian countries were large enough to "bring down" countries under the dynamic of herding we have discussed above, the exposures were not big enough to bring down foreign banks. One of the key challenges is to realign the incentives of regulators to worry about the concentration of exposures in foreign countries as well as in local banks.

Let us add another dimension to our nightmare scenario. Further assume that a country has recently signed up to the Special Data Dissemination Standard (SDDS) - one of the lasting responses of the 1995 Tequila crisis - and the 1999 Code of Good Practice, and as a result, has started publishing its foreign exchange reserves daily. In this case bankers and investors with more modest exposures would observe that as risks grow - prices are falling and volatility rising - other bankers and investors are leaving the country rapidly. In this heightened environment they will view the country's loss of reserves as doubly increasing the risk that they are left wrong and alone. This will trigger a further rush for the exit.

The reason why this is a major challenge to the current regulatory framework is that herding is frequent and that even short-lived financial crises have real economic impact. While herding behaviour 
is hard to prove directly given the paucity of reliable data on the positions of financial institutions, there is a now a growing body of evidence that markets behave as if market participants herd.

In the foreign exchange markets for example, if we define a crash as a $10 \%$ fall in the real exchange rate over three months, there have been 78 crashes across 72 countries since the EMS crisis began in September 1992. These are not distributed evenly over time or distributed with deteriorating fundamentals, but they cluster. Contagion is rife with $70 \%$ of crashes occurring in just three years. This contagion does not move predictably along the lines of trade, but along the lines of shared investors. The stepping-stones of the most recent crisis, for example, were from Thailand and Indonesia to Korea, on to Russia and then to Brazil. These countries share very little trade in common. Furthermore, crashes are invariably preceded by booms as the herd moves into place. Chart 2 shows the number of foreign exchange crashes per year across 72 countries as bars and the annual crossborder portfolio flows into emerging markets as a line. Note how investors rushed into emerging markets in 1995 and 1996, prior to the crashes in 1997 and 1998.

Further evidence of herding and the problems of a static value-at-risk analysis can be found by looking at the distribution of daily market returns. In Chart 3 , we imagine we are a risk manager in January 1997 looking at the distribution of daily returns of a portfolio of OECD currencies versus the dollar over the previous five years. The distribution is well behaved and fairly symmetrical - though not around zero. According to this actual distribution she would expect a more than $1 \%$ decline in this portfolio's value in a day around $5 \%$ of the time. Three years later and if she survived, she would have found that her portfolio fell by more than $1 \%$ in a day more than $10 \%$ of the time and the distribution of returns looked very different (Chart 4 ). (It can be shown that the difference between these two distributions follows a beta distribution consistent with herding behaviour.)

\section{Chart 2}

\section{"Crashes" and "booms" in the foreign exchange market}

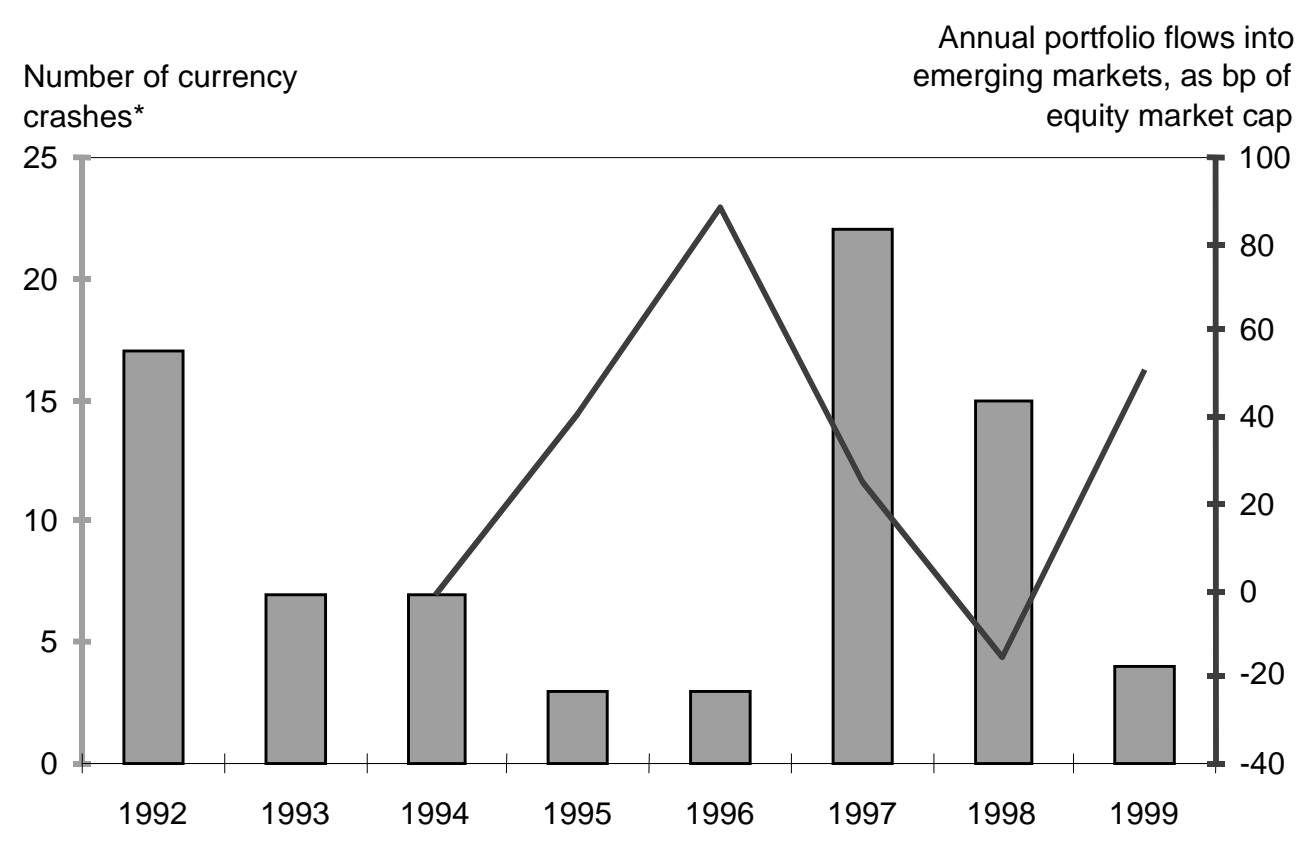

Source: State Street Bank.

The predominance of herding behaviour and its lethal combination with the practice of DEAR limits may explain why the 1990s have been such a decade of financial dislocation: the financial system has been in crisis for 40 out of the 120 months or $33 \%$ of the time. This instability has real economic impact. Although international portfolio flows have recovered from dips in 1998, they remain highly concentrated in just five markets: Hong Kong, Korea, Singapore and Taiwan - hardly the most capital needy countries either given their high domestic savings and big current account surpluses. Many other markets have found it hard to raise foreign capital. 


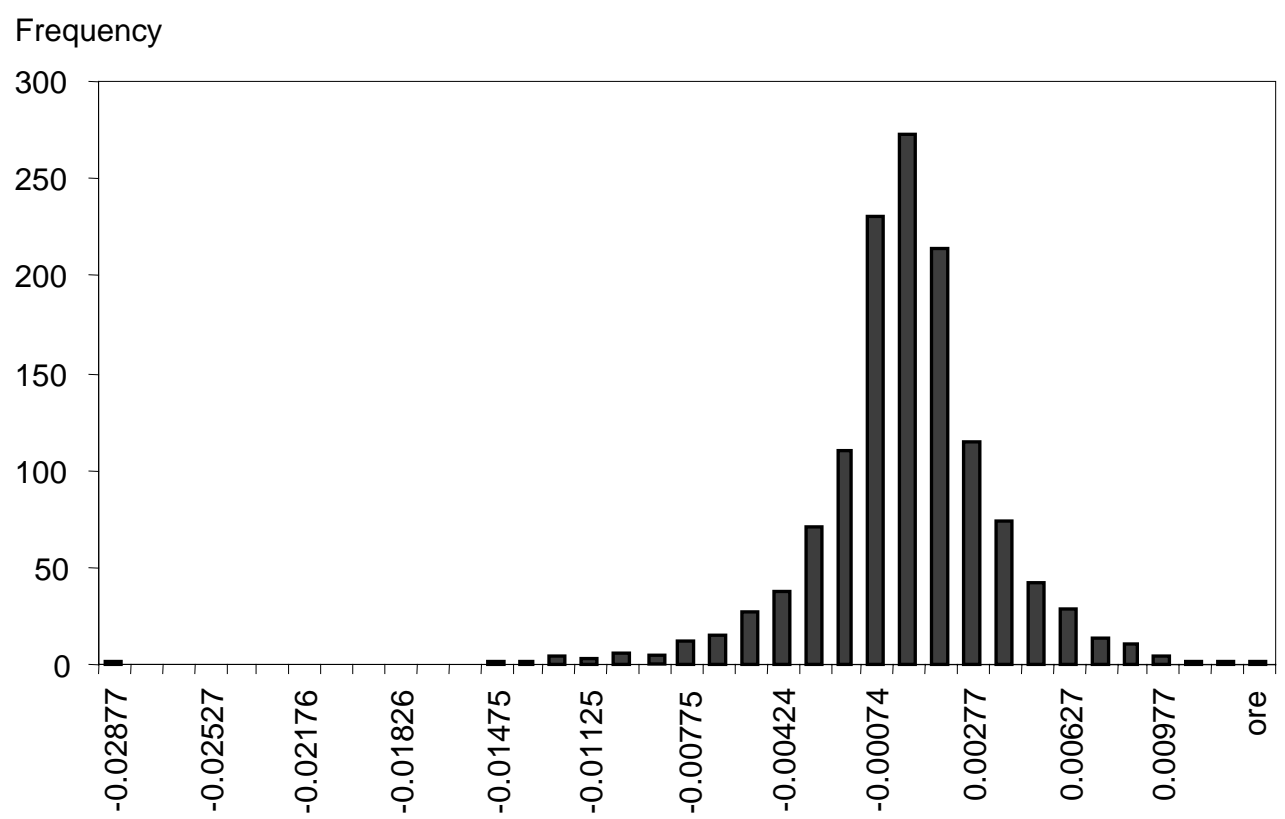

These financial crises also have a direct impact on GDP. For example, while there has been a strong rebound in GDP in 1999 in Asia in general and in South Korea in particular, the rebound has not offset the loss of GDP during the crisis period. One way of estimating the lost GDP of the Asian crisis is to estimate where GDP would be today if Asian economies had continued the more modest but sustainable growth rates experienced in the five years before their current account deficits began to widen in 1993-94. Were it not for the crisis and its preceding boom, GDP would be an aggregate of USD 130 billion higher in South Korea, Thailand, Malaysia and Indonesia. Another measure of this lasting impact is the elevation of poverty levels in Asia today compared with 1997.

Frequency

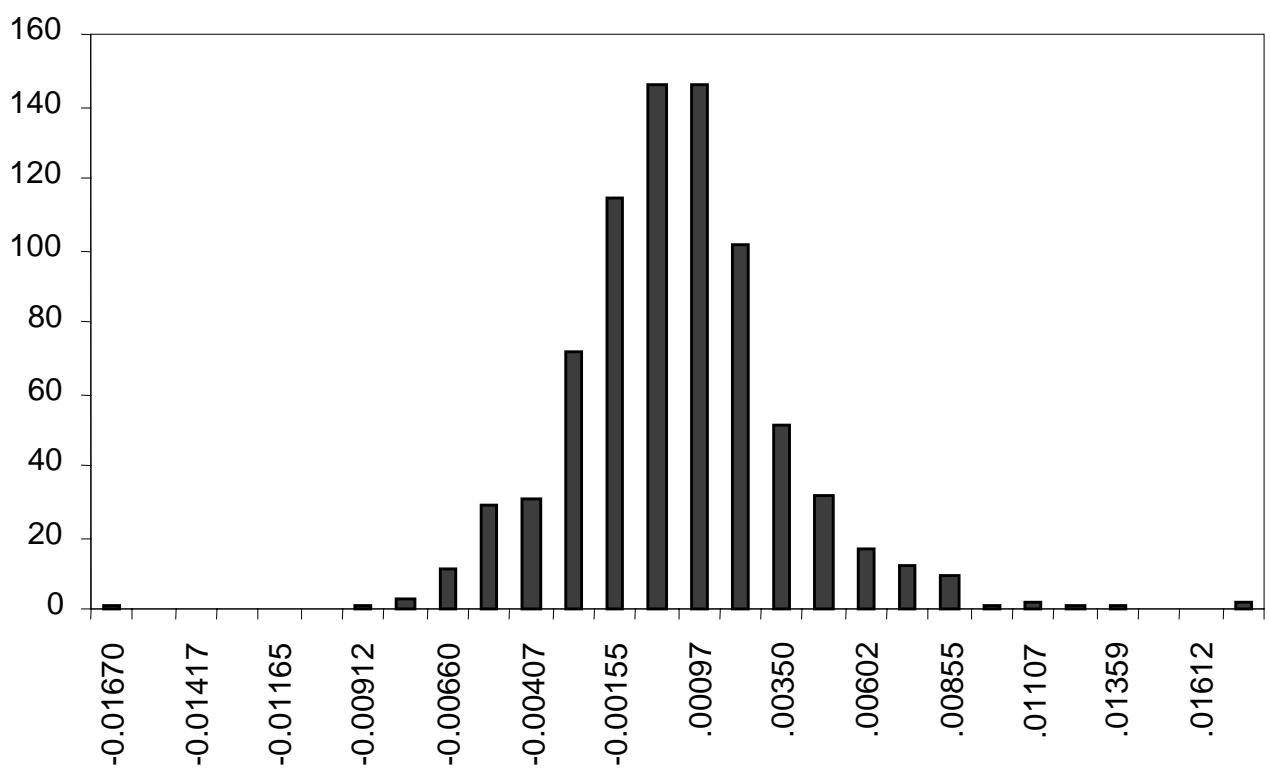


The paradox is that if one or two banks followed a DEAR limit and others did not, those banks would have an effective risk management system that at the margin would support the financial system. But if every bank were to follow the same approach, given that these banks follow each other into and out of markets, the DEAR limit would contribute to systemic risk. It is ironic therefore that the Basel Committee on Banking Supervision is supporting the rapid adoption of these systems across all banks and encouraging investors to follow suit, for an early reference see "An internal model-based approach to market risk capital requirements", Bank for International Settlements, Basel, 1995. There is a further paradox with transparency. The more herding investors and banks know about what each other are up to the more unstable markets may become. In the long run transparency and DEAR limits are a good development, but they are harmful in the short-run in the context of herding behaviour.

\section{What should policymakers and regulators do?}

Herding presents a classic example of the need for intervention. The individual incentives of herding investors create systemic risks. Moreover, if regulators were so coordinated that they behaved like one global regulator, they would be best placed to make an intervention. Through the privileged formation they have as a regulator of individual bank balance sheets they know when banks are herding. This requires a different focus. Today regulators are warned by other regulators when banks in their jurisdiction have exposures that threaten themselves, not whether banks around the world have exposures which together threaten a foreign market and could become contagious.

However, if this information were made public, in the context of herding investors, random shocks could quickly evolve into financial crises. But how should regulators respond if they notice herding in a particular market? They should require the bank to put aside an extra amount of capital for "strategic risk" without specifying which markets carry that risk. Applying tighter risk management requirements for those specific markets in which the herd has appeared will only make the stampede more vicious when negative news strikes. Collateral requirements are like a tax on banks and are very unpopular. However, banks could be given the choice of either putting up strategic collateral from time to time, or by buying liquidity options from the central bank during good times.

Whether these solutions would work or not, the whole concept of market-sensitive risk management practices needs to be seriously reconsidered in the context of herding and the authorities should rethink their extension to the use of credit rating agencies and the risk management of long-term investors.

It is arguable that regulators have actually promoted herding through risk management systems. They may also have done so in their zeal for disclosure of bank positions and central bank reserves. Indeed, there is a role for one unregulated investor who is encouraged to buy near the bottom of markets through the absence of risk, capital disclosure and credit concerns. Such investors would make the system safer but would be high risk and so should be restricted to those who can afford to lose. If this investor had to be invented she would look something like a hedge fund. Interestingly, as the bigbetting hedge funds have been undermined by the disclosure and credit policies of banks, market liquidity has fallen and volatility has risen. Just as the big macro hedge funds fade away we may find that they supported the market as much as they exploited it.

Those of you unable to stomach regulators promoting hedge funds will be relived to note that there are other kinds of flows that do not herd so much, foreign direct investment for example. Further, during the Mexican and Asian crises, equity portfolio flows also revealed less herding than bond flows. It would appear that bond investors are keen to get out before they are held in by a debt moratorium or orderly work out. This raises some interesting questions for those trying to build in burden-sharing and orderly work out provisions into bond constitutions.

Transparency in data and governance is clearly a good thing in the long-run and promotes the right behaviour of governments. Governments should be encouraged to disclose more information every month and quarter, but not on a daily basis. In an environment of herding investors, there is not a good case for insisting that countries release central bank reserve data with such high frequency. It is telling that during the EMS crisis, many of the developed countries that have just adopted the Code of Good Practice on Transparency found it helpful to delay the monthly publication of their official reserves or to camouflage its information for several months. Small vulnerable emerging markets will find it even more helpful not to publish their reserves every day or every week and should not be forced to do so. 